\title{
Corrosion Resistance of Electroless Ni-Cu-P Ternary Alloy Coatings in Acidic and Neutral Corrosive Mediums
}

\author{
Mbouillé Cissé, Mohamed Abouchane, Tayeb Anik, Karima Himm, Rida Allah Belakhmima, \\ Mohamed Ebn Touhami, Rachid Touir, and Abderrahmane Amiar
}

Laboratory of Electrochemistry, Corrosion and Environment, Faculty of Science, P.O. Box 133, Kenitra, Morocco

Correspondence should be addressed to Mbouillé Cissé, c.mbouille@gmail.com

Received 20 July 2010; Revised 17 October 2010; Accepted 25 October 2010

Academic Editor: Jerzy A. Szpunar

Copyright () 2010 Mbouillé Cissé et al. This is an open access article distributed under the Creative Commons Attribution License, which permits unrestricted use, distribution, and reproduction in any medium, provided the original work is properly cited.

\begin{abstract}
Electroless Ni-Cu-P alloy coatings were deposited on the ordinary steel substrate in an acidic hypophosphite-type plating bath. These coatings were characterized by a scanning electron microscope (SEM) and an X-ray diffraction. The micrograph shows that coating presents a nodular aspect and is relatively homogeneous and very smooth. The EDX analysis shows that the coating contains $12 \mathrm{wt} . \%$ of phosphorus element with a predominance of nickel element. In addition, the anticorrosion properties of the Ni-Cu-P coatings in $1 \mathrm{M} \mathrm{HCl}, 1 \mathrm{M} \mathrm{H}_{2} \mathrm{SO}_{4}$, and $3 \% \mathrm{NaCl}$ solutions were investigated using Tafel polarization curves, electrochemical impedance spectroscopy, and SEM/EDX analysis. The result showed a marginal improvement in corrosion resistance in $3 \% \mathrm{NaCl}$ solution compared to acidic medium. It also showed that the corrosion mechanism depends on the nature of the solution.
\end{abstract}

\section{Introduction}

Interest in electroless plating of nickel-based ternary alloys has increased because of their excellent corrosion, wear, thermal and electrical resistance. They also possess good magnetic properties [1-4].

Many metal elements, such as copper, zinc, iron, cobalt, tungsten, molybdenum, and rhenium can be codeposited in an Ni-P matrix to improve some properties $[5,6]$. The choice of these elements depends on the applications sought after. The applications of Ni-Cu-P in VLSI $[7,8]$ and in thin-film memory discs [9] were considered.

Copper content in electroless $\mathrm{Ni}-\mathrm{Cu}-\mathrm{P}$ alloy coatings depends mainly on $\mathrm{pH}$, temperature, and $\mathrm{Cu}^{2+}$ concentration in electrolyte composition and has a significant effect on the corrosion resistance of the coatings [10]. In order to get the stability and the acceleration role of ion $\mathrm{Cu}^{2+}$, some researchers have achieved developing $\mathrm{Ni}-\mathrm{Cu}-$ $\mathrm{P}$ baths by adding small amount of copper in Ni-P baths $[11,12]$. In addition, it was reported that the inclusion of $\mathrm{Cu}$ in electroless Ni-P coatings improves their smoothness, brightness, anti-corrosion and also increases the deposit rate and surface hardness $[13,14]$.
Over recent decades, investigations were conducted on the corrosion behaviour of electroless Ni-Cu-P coatings but their corrosion mechanism is still under discussion. However, studies on corrosion resistance of ternary deposits show that the influence of a metallic element codeposited in the matrix Ni-P depends on its ability to form a stable oxide in the media as $\mathrm{pH}$ and potential. Thus, studying the behaviour of ternary Ni-X-P alloy $(\mathrm{X}=\mathrm{Mo}, \mathrm{W})$ showed that in $\mathrm{H}_{2} \mathrm{SO}_{4}$ media, Ni-W-P coating slightly improves its corrosion resistance compared with Ni-P alloy, while the Ni-Mo-P coating had no effect on the corrosion characteristics [15]. The same observations were made on the study of corrosion of electroless Ni-Co-P deposit on aluminum substrate in 5\% $\mathrm{H}_{2} \mathrm{SO}_{4}$ media, where a deposit of $8.3 \mathrm{wt}$.\% Co represents the best requirements for high corrosion resistance and high electromagnetic shielding effect according to that study [16].

Electroless Ni-Cu-P deposits have better corrosion resistance than Ni-P or copper $[10,17]$, or stainless steel in alkaline $50 \% \mathrm{NaOH}$ [18]. Similar results were obtained in $5 \% \mathrm{NaCl}$ and $0.5 \mathrm{M} \mathrm{H}_{2} \mathrm{SO}_{4}$ media [19].

In this paper, the characterisation of electroless $\mathrm{Ni}-\mathrm{Cu}-\mathrm{P}$ alloy coatings and its anti-corrosion properties in $1 \mathrm{M} \mathrm{HCl}$, $1 \mathrm{M} \mathrm{H}_{2} \mathrm{SO}_{4}$, and $3 \% \mathrm{NaCl}$ solutions were investigated and 
were compared using electrochemical measurement and SEM/EDX.

\section{Experimental Procedure}

2.1. Materials. Ordinary steel $(15 \mathrm{~mm} \times 10 \mathrm{~mm} \times 0.35 \mathrm{~mm})$ with a composition (in wt.\%) of: $\mathrm{C}=0.11, \mathrm{Si}=0.24$, $\mathrm{Mn}=0.47, \mathrm{Cr}=0.12, \mathrm{Mo}=0.02, \mathrm{Ni}=0.1, \mathrm{Al}=0.03$, $\mathrm{Cu}=0.14, \mathrm{~W}=0.06, \mathrm{Co}<0.0012, \mathrm{~V}<0.003$ and the remainder iron was used as the substrates. The specimen was polished with abrasive emery papers from 400-1000 grade soaked in commercial cleaning solution and dried with pulse air. The deposit rate for plating of one hour was measured from simple weight gains.

2.2. Electroless Ni-Cu-P Plating and Corrosion Mediums. Ni$\mathrm{Cu}-\mathrm{P}$ coating layer was chemically deposited from electroless bath comprising of $\mathrm{NiSO}_{4}, 6 \mathrm{H}_{2} \mathrm{O} 0.1 \mathrm{M} ; \mathrm{CuSO}_{4}, 5 \mathrm{H}_{2} \mathrm{O}$ $0.0008 \mathrm{M} ; \mathrm{NaH}_{2} \mathrm{PO}_{2}, \mathrm{H}_{2} \mathrm{O} 0.28 \mathrm{M} ; \mathrm{Na}_{3} \mathrm{C}_{6} \mathrm{H}_{5} \mathrm{O}_{7}, 2 \mathrm{H}_{2} \mathrm{O}$ $0.2 \mathrm{M}$, and $\mathrm{CH}_{3} \mathrm{COONH}_{4}$. The $\mathrm{pH}$ is fixed at 5 with the addition of acetic acid; the temperature was held at $78^{\circ} \mathrm{C}$. The details of the plating process are described elsewhere [20]. To minimise the influence of the thickness of the coating on electrochemical measurement parameters, all the samples were deposited to have a similar thickness of about $8 \mu \mathrm{m}$.

Molar Sulfuric, hydrochloric acids solutions, and 3\% sodium chloride solution were used as corrosive mediums.

2.3. Electrochemical Measurements. The electrochemical measurements were performed in a typical three-compartment glass cell consisted of the ordinary mild steel rod as working electrode and a platinum mesh as a counter electrode. The specimens of working electrode were machined into cylinders and mounted in polytetrafluoroethylene (PTFE) moulds. The area which is in contact with the corrosive solution was $1 \mathrm{~cm}^{2}$. The reference electrode was a saturated calomel electrode with all potentials referred. The potentiodynamic measurements were carried out using VoltaLab PGZ 100, which was controlled by a personal computer. The working electrode was immersed in test solution for 1 hour until a steady state was obtained. The polarization curve was recorded by polarization from -0.9 to $0.2 \mathrm{~V} /$ sce under potentiodynamic conditions corresponding to $1 \mathrm{mV} / \mathrm{s}$ (sweep rate).

The linear Tafel segments of curves were extrapolated to corrosion potential for obtaining the corrosion current density values. The protective efficiency $E_{I}(\%)$ from the polarization curves was calculated from the following equations:

$$
E_{I}(\%)=\left(1-\frac{i_{\text {corr }}}{i_{\text {corr }}^{0}}\right) \times 100,
$$

where $i_{\text {corr }}^{0}$ and $i_{\text {corr }}$ are the corrosion current values without and with alloy coating of substrate, respectively.

The electrochemical impedance spectroscopy measurements were carried out with a small amplitude ac. Signal $(10 \mathrm{mV} / \mathrm{rms})$, over a frequency domain from $100 \mathrm{KHz}$ to $10 \mathrm{mHz}$. The EIS spectra analysis was performed using

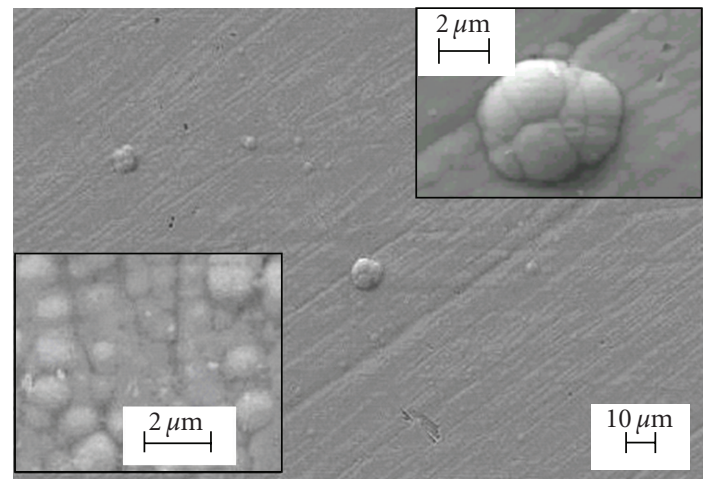

FIGURE 1: SEM image of Ni-Cu-P alloy deposit: two magnifications of nodules are shown.

Boukamp impedance analysis software [21]. The charge transfer resistance $R_{\mathrm{ct}}$ is obtained from the diameter of the semicircle in Nyquist representation. The protective efficiency $E_{Z}$ via the impedance curves of the coating was found from the following relationship:

$$
E_{Z}(\%)=\left(1-\frac{R_{\mathrm{ct}}^{\circ}}{R_{\mathrm{ct}}}\right) \times 100
$$

where $R_{\mathrm{ct}}^{0}$ and $R_{\mathrm{ct}}$ are the charge transfer resistance values without and with alloy coating of substrate, respectively.

2.4. Scanning Electronic Microscope. The surfaces of ordinary steel without and with alloy coating were immersed for 55 hours in different corrosives media and were analyzed by scanning electronic microscope JEOL JSM-5500 type.

\section{Results and Discussion}

3.1. Coating Characterizations. SEM picture of Ni-Cu-P coatings film on ordinary steel surface is presented in Figure 1. This micrograph shows that coating presents a nodular structure with same grain size and is relatively homogeneous and very smooth deposit. The nodules diameter is below $5 \mu \mathrm{m}$ according to copper content $12 \mathrm{wt} \%$. [20]. The EDX analysis shows that the coating contains $12 \mathrm{wt} \%$ of phosphorus element with a predominance of nickel element (Figure 2).

The crystalline peaks in Figure 3 resulted from the Fe substrate. A broad peak appearing around 0 of $45^{\circ}$ indicates that the deposits are amorphous. This is in correspondence that the electroless nickel deposit would become amorphous when its percentage of phosphorus is above $7 \mathrm{wt} \%$ [22-24].

\subsection{Corrosion Study}

\subsubsection{Acidic Media}

(i) Polarization Curves. The corrosion behaviour of the ordinary steel and the coating was measured at room temperature with polarization curves measurement in $1 \mathrm{M} \mathrm{H}_{2} \mathrm{SO}_{4}$ and $1 \mathrm{M} \mathrm{HCl}$. 


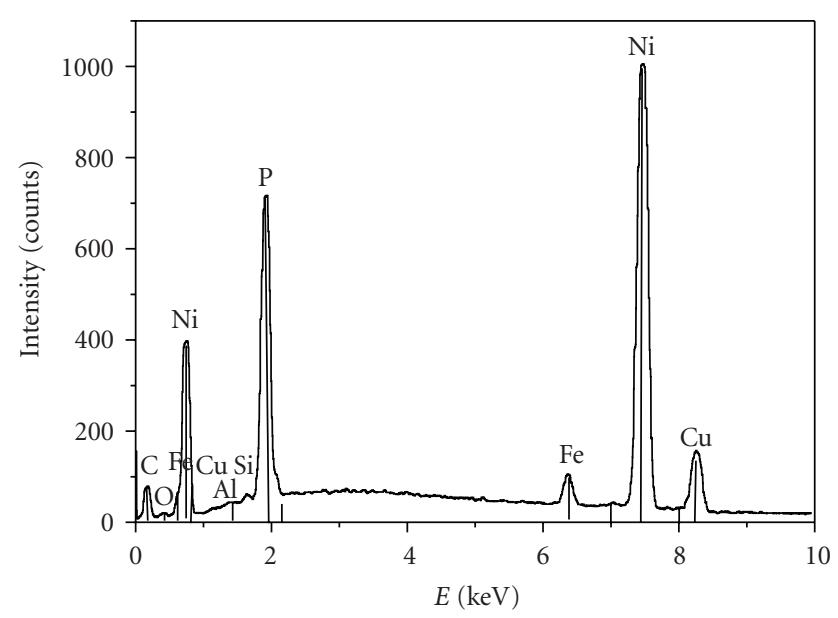

Figure 2: EDX spectra of Ni-Cu-P alloy coatings.

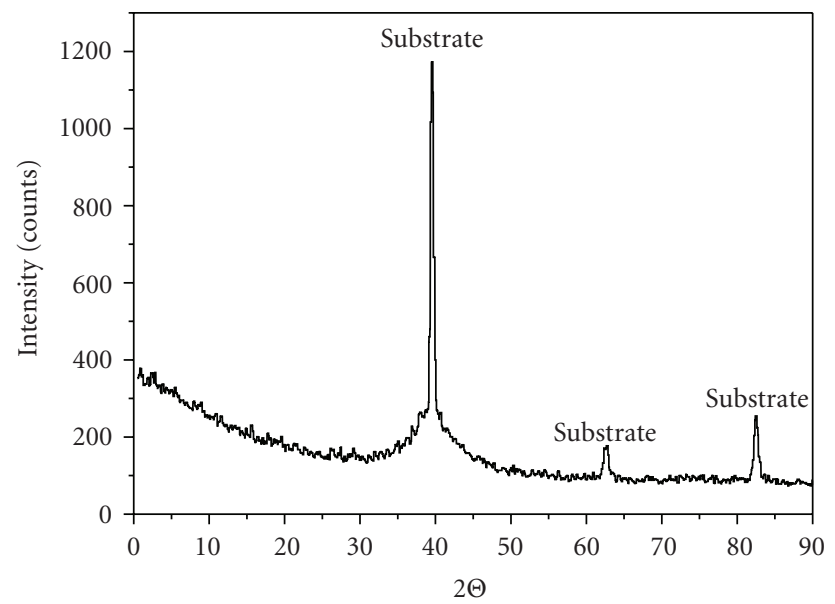

Figure 3: X-ray diffraction for Ni-Cu-P alloy coatings.

Figure 4 shows a typical corrosion behaviour of electroless $\mathrm{Ni}-\mathrm{Cu}-\mathrm{P}$ alloy in both acid media.The shape of the overall polarization curve of coating obtained in $1 \mathrm{M} \mathrm{H}_{2} \mathrm{SO}_{4}$ medium is similar to those found by some authors for electroless $\mathrm{NiP}$ alloys in $\mathrm{NaCl}, \mathrm{HCl} \mathrm{Na} \mathrm{SO}_{4}$, and $\mathrm{H}_{2} \mathrm{SO}_{4}$ environments by Carbajal et al. [25], Diegle et al. [26], Niass et al. [27], and Elsener et al. [28]. We observe from this that the cathodic current density is independent of coating. However, in the anodic range, the current density decreases dramatically in the presence of $\mathrm{Ni}-\mathrm{Cu}-\mathrm{P}$ coating. This indicates the good resistance of this coating.

The results also show a slight tendency to passivation in molar sulfuric acid as well as in hydrochloric acid medium by the appearance of a current plateau in the anodic polarization. The existence of this current plateau has been reported on these types of alloys [25-28]. We can note two anodic distinct slopes, one in the field of potential directly below $-0.35 \mathrm{~V}$ and a second grade between -0.35 and $0.4 \mathrm{~V}$. Beyond $-0.35 \mathrm{~V} / \mathrm{SCE}$ the current exhibited a plateau which may be attributed to a diffusion limited process. It is well known that the phosphorus content is strongly
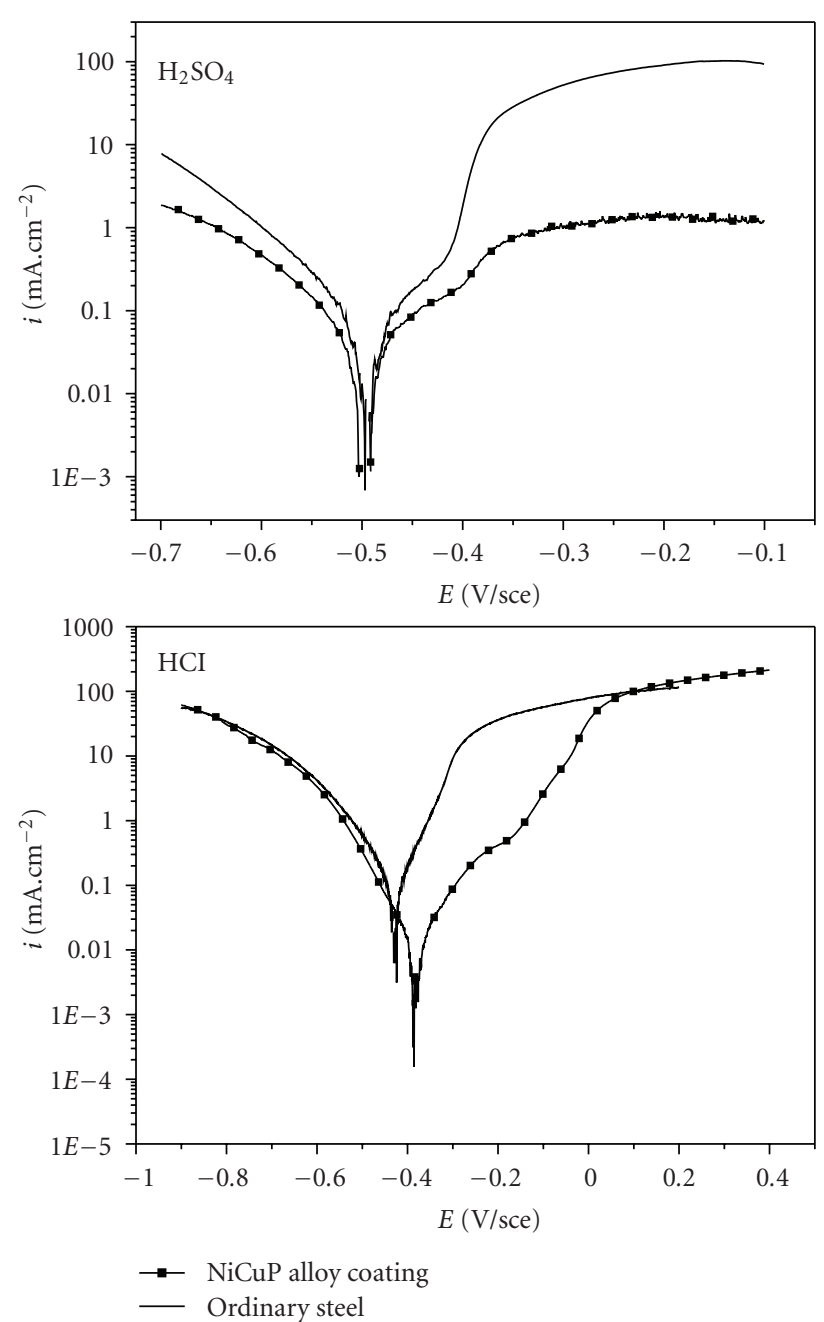

Figure 4: Polarization curves of Ni-Cu-P alloy coatings and steel substrate in both acidic media.

linked to the crystalline state. The formation of a P-rich surface film at the alloy/solution interface is a consequence of rapid and selective nickel dissolution. This dissolution process is controlled via diffusion of nickel through this phosphorus-rich zone [29-32]. Some authors showed that an increase of the copper content promotes a best anticorrosion performance of these electroless coating [17]. Otherwise, Liu et al. [33] have shown that the introduction of $\mathrm{Cu}$ element in Ni-P coating plays important roles in enhancing the corrosion resistance of $\mathrm{Ni}-\mathrm{Cu}-\mathrm{P}$ coating. Indeed, the $\mathrm{Cu}$ element accelerates the selective dissolution of nickel, resulting in the enrichment of $\mathrm{P}$ and $\mathrm{Cu}$ elements in the surface layer of $\mathrm{Ni}-\mathrm{Cu}-\mathrm{P}$ coating. However, they describe a passivation process at the surface which blocks the contact of coating surface with corrosive solution. As we can see, the current arrest which is followed by an increase in the polarization curves allows us to rule out the classical passivation mechanism by hydroxide formation recognized for pure nickel $[34,35]$. According to other publications, the preferential dissolution of the surface enriched in the external phosphorus reacts with water to form a layer of 
TABLE 1: Impedance data of Ni-Cu-P alloy coatings and uncovered ordinary steel after two hours of immersion in acid media.

\begin{tabular}{|c|c|c|c|c|c|c|}
\hline & & $R_{\mathrm{ad}}\left(\Omega \cdot \mathrm{cm}^{2}\right)$ & $C_{\mathrm{ad}}\left(\mu \mathrm{F} \cdot \mathrm{cm}^{-2}\right)$ & $R_{\mathrm{ct}}\left(\Omega \cdot \mathrm{cm}^{2}\right)$ & $C_{\mathrm{ct}}\left(\mu \mathrm{F} \cdot \mathrm{cm}^{-2}\right)$ & $E_{Z}(\%)$ \\
\hline \multirow{2}{*}{$\mathrm{H}_{2} \mathrm{SO}_{4} 1 \mathrm{M}$} & Uncovered ordinary Steel & - & - & 290 & 51 & - \\
\hline & NiCuP coating & 513 & 45.6 & 108 & 12.5 & 43 \\
\hline \multirow{2}{*}{$\mathrm{HCl} 1 \mathrm{M}$} & Uncovered ordinary Steel & - & - & 405 & 60 & - \\
\hline & NiCuP coating & 863 & 30.5 & 73.5 & 46 & 53 \\
\hline
\end{tabular}

hypophosphite $\mathrm{H}_{2} \mathrm{PO}_{2}{ }^{-}$anions $[26,28,35]$. This layer in turn will block the supply of water to the electrode surface, thereby preventing the hydration of nickel $[36,37]$ which is considered to be the first step to form soluble $\mathrm{Ni}^{2+}$ species. The presence of phosphorus-rich surface layer in a highphosphorus electroless nickel deposit has been confirmed even before it is subjected to any corrosive environment [30].

(ii) Electrochemical Impedance Spectroscopy. Figure 5 shows the fitting and experimental data of Nyquist diagrams, which are obtained after two hours of immersion in both acidic media for ordinary steel substrate coating and uncoating by electroless $\mathrm{Ni}-\mathrm{Cu}-\mathrm{P}$. In the absence of $\mathrm{Ni}-\mathrm{Cu}-\mathrm{P}$ alloy coating, the plots consist of one semicircle which may be devoted to the response of a combination of resistance transfer $\left(R_{\mathrm{ct}}\right)$ and capacitance $\left(C_{\mathrm{ct}}\right)$. In the presence of $\mathrm{Ni}-\mathrm{Cu}-\mathrm{P}$ alloy coatings, the plots consist of two semicircles: the first which is located between $100 \mathrm{kHz}$ and $100 \mathrm{~Hz}$ (at high frequency) may be attributed to the adsorbed film, but the second one is the response of charge transfer resistance $R_{\mathrm{ct}}$. This resistance increases in the presence of $\mathrm{Ni}-\mathrm{Cu}-\mathrm{P}$ alloy coatings. These comments were reported in the study of the Ni-P alloy in acid media by other authors [27]. They attributed the first loop to the capacity of an adsorbed film which is due to the oxide layer formation.

To account for the corrosion behaviour of steel substrate and $\mathrm{Ni}-\mathrm{Cu}-\mathrm{P}$ coatings in the acidic media at the open circuit potentials, an equivalent electrical circuit model given in Figure 6 is used to simulate the metal/solution interface and analyze the Nyquist diagrams. It mainly consists of the following elements: solution resistance of the electrolyte $\left(R_{s}\right)$, adsorption capacitance $\left(C_{\mathrm{ad}}\right)$, adsorption resistance $\left(R_{\mathrm{ad}}\right)$, charge transfer capacitance $\left(C_{\mathrm{ct}}\right)$, and charge transfer resistance of the electrode/solution interface $\left(R_{\mathrm{ct}}\right)$.

From the Table 1, we can say that the electroless Ni-Cu-P alloy coatings improve the corrosion resistance of ordinary steel in both acidic media.

\subsubsection{Neutral Media}

(i) Polarization Curves. The polarization curves of ordinary steel substrate coated and uncoated by electroless Ni-Cu-P alloy in $3 \% \mathrm{NaCl}$ after two hours of immersion are presented in Figure 7. The examined alloy coating shifted the corrosion potential $\left(E_{\text {corr }}\right)$ towards more anodic potentials. This shift is about $275 \mathrm{mV} / E_{\text {corr }}$. In the cathodic range, the Tafel slopes were not changed by the coating. However, in the anodic range, a significant decrease in the anodic current densities was observed in the presence of alloy. These results further

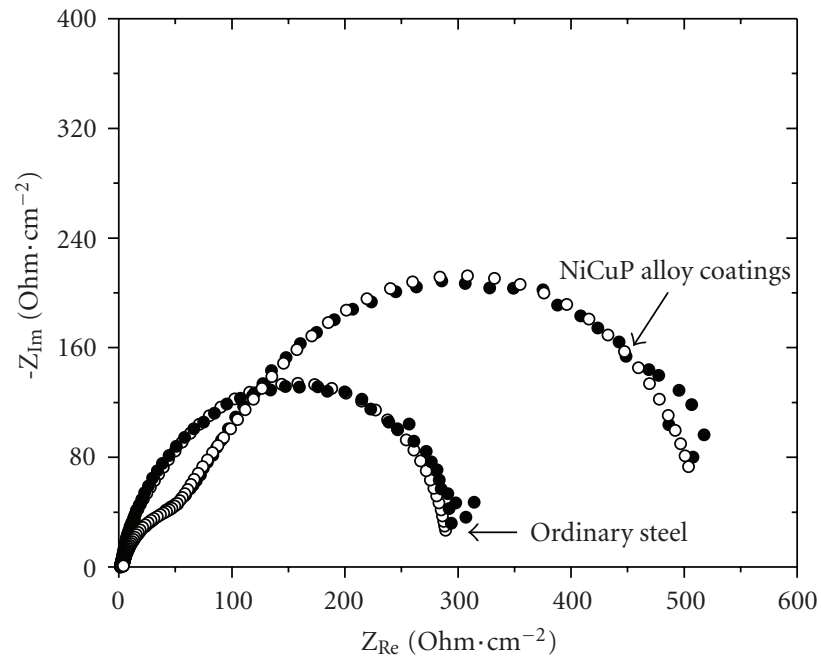

(a)

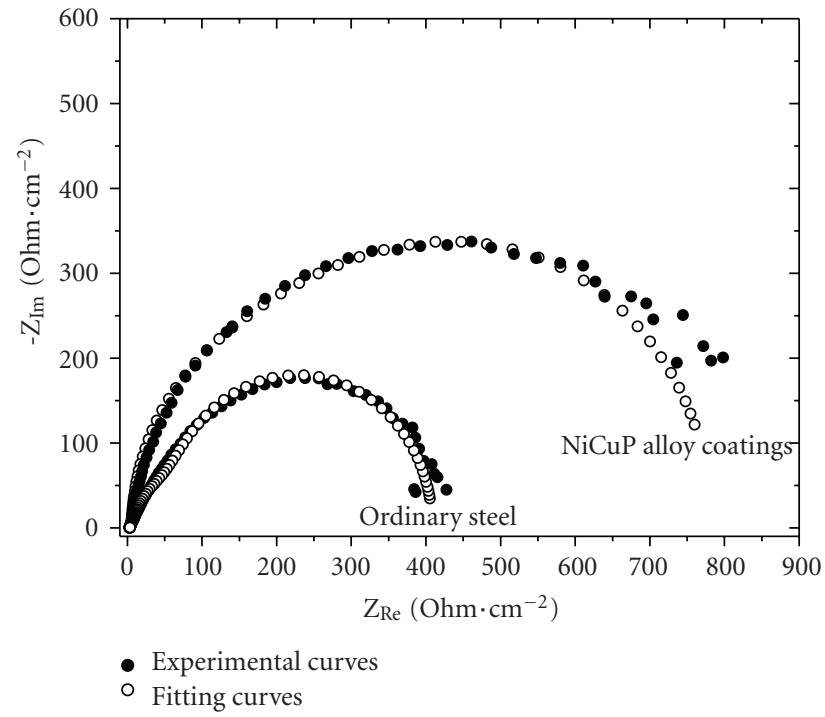

(b)

FIGURE 5: Experimental and fitting of Nyquist diagrams with and without Ni-Cu-P alloy coatings for two hours of immersion in: (a) $1 \mathrm{M} \mathrm{H}_{2} \mathrm{SO}_{4}$ and (b) $1 \mathrm{M} \mathrm{HCl}$.

confirmed that these coatings can be used for corrosion protection application in salty environments (Table 2). No passivity tendency was observed in the measurement range, which is consistent with the work of Mimani and Mayanna [38].

In an early investigation on electroless $\mathrm{Ni}-\mathrm{Cu}_{2,6}-\mathrm{P}_{11,3}$ and $\mathrm{Ni}-\mathrm{P}_{11}$ coatings, values of $0.7 \mu \mathrm{A} / \mathrm{cm}^{2}$ and $24 \mu \mathrm{A} / \mathrm{cm}^{2}$ were 

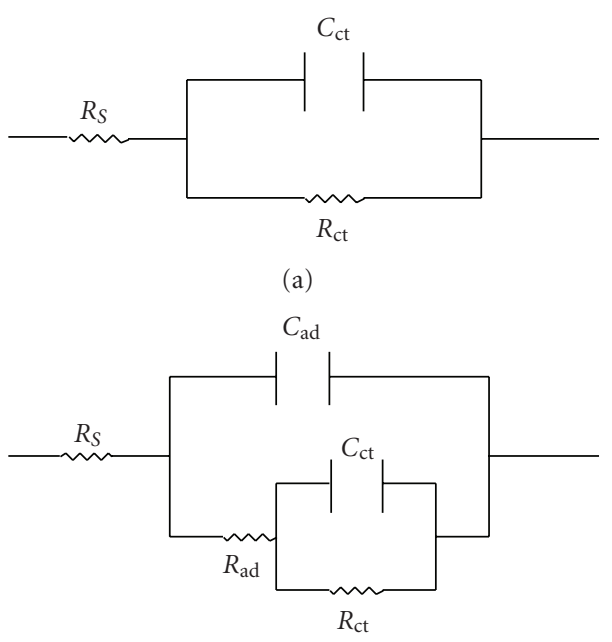

(b)

FIGURE 6: Equivalent circuit for impedance analysis: (a) ordinary Steel (b): Ni-Cu-P alloy coating. $R_{s}$ : Solution resistance; $R_{\mathrm{ct}}$ : charge transfer resistance; $C_{\mathrm{ct}}$ : charge transfer capacitance; $R_{\mathrm{ad}}$ : adsorption film resistance; $C_{\mathrm{ad}}$ : adsorption film capacitance.

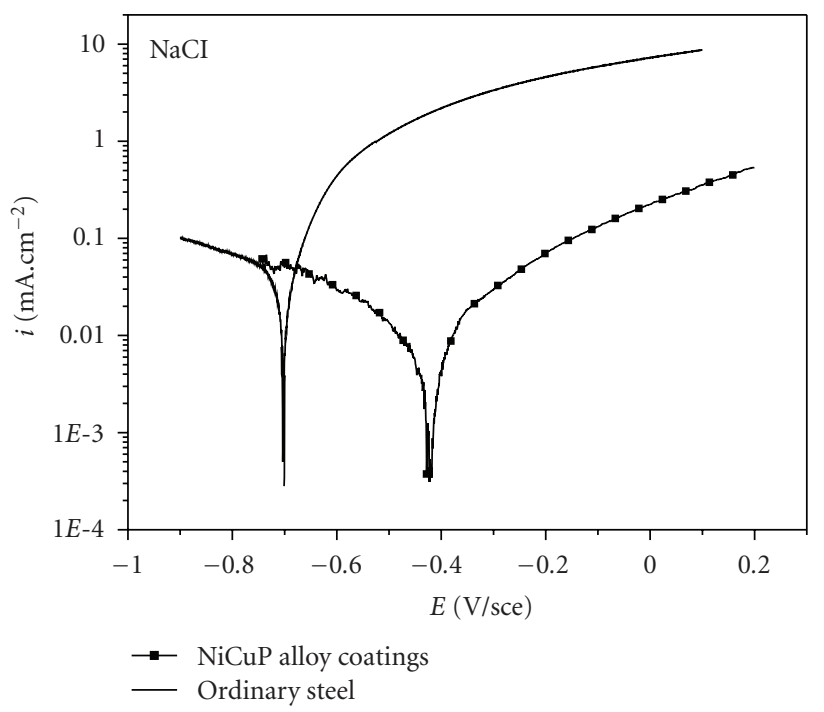

Figure 7: Polarization curve of ordinary steel substrate covered and uncovered by Ni-Cu-P alloy in $3 \% \mathrm{NaCl}$ after two hours of immersion.

measured in 5\% $\mathrm{NaCl}$, respectively [19]. In $\mathrm{NaCl}$ solution with $4-20 \%$, a corrosion rate of the electroless deposits $\mathrm{Ni}$ coating is $0.5-2 \mu \mathrm{m} /$ year $[37,39]$. Crobu et al. [28] in their recent work found a range of current density $0.5-0.7 \mu \mathrm{A} / \mathrm{cm}^{2}$ which is in concordance with our work. Similar corrosion rates were also found for $\mathrm{Ni}-\mathrm{P}$ which has the phosphorus content higher than 16-18wt.\% [40-42], and comparable results were obtained by Liu et al. [17] for stainless steel substrate.

(ii) Electrochemical Impedance Spectroscopy. Figure 8 shows the Nyquist diagrams of ordinary steel and electroless $\mathrm{Ni}-\mathrm{Cu}$ $\mathrm{P}$ alloy coatings, respectively, in 3\% sodium chloride solution

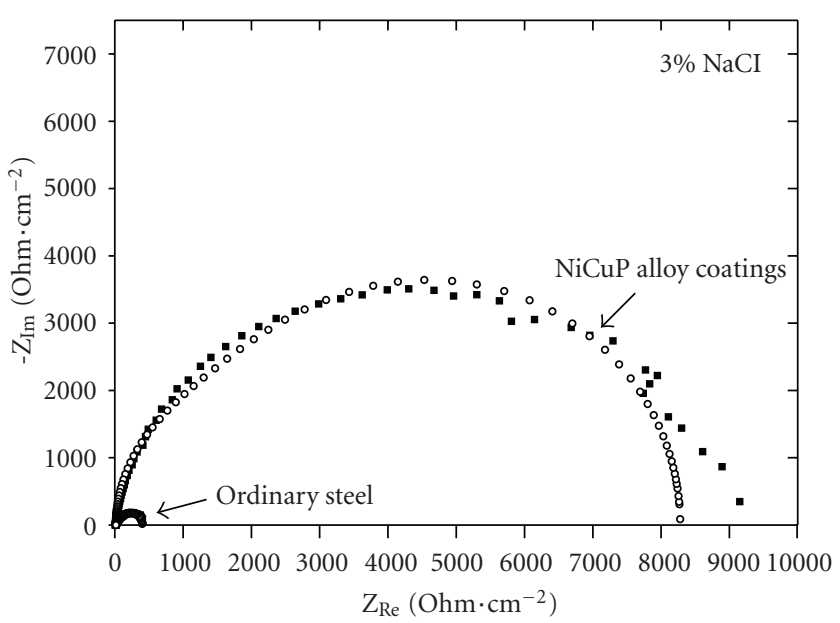

- Experimental curves

- Fitting curves

FIGURE 8: Experimental and fitting of Nyquist diagrams with and without Ni-Cu-P alloy coatings for two hours of immersion in 3\% $\mathrm{NaCl}$.

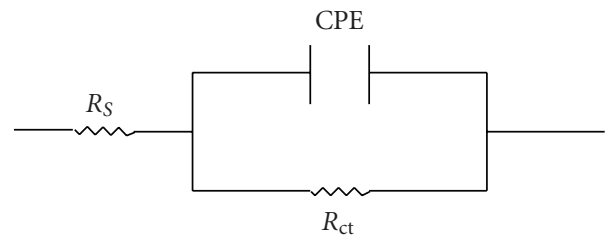

Figure 9: Equivalent circuit for impedance analysis of steel substrate and $\mathrm{Ni}-\mathrm{Cu}-\mathrm{P}$ alloy coatings in $3 \% \mathrm{NaCl}$. $R_{s}$ : solution resistance; $R_{\mathrm{ct}}$ : charge transfer resistance; CPE: constant phase element.

TABLE 2: Electrochemical parameters of Ni-Cu-P alloy coatings and uncovered ordinary steel after two hours of immersion in $3 \% \mathrm{NaCl}$.

\begin{tabular}{lccc}
\hline & $E_{\text {corr }}(\mathrm{mV} / \mathrm{sce})$ & $i_{\text {corr }}\left(\mu \mathrm{A} \cdot \mathrm{cm}^{-2}\right)$ & $E_{P}(\%)$ \\
\hline $\begin{array}{l}\text { Uncovered ordinary } \\
\text { steel }\end{array}$ & -703 & 43 & - \\
NiCuP coating & -428 & 4.8 & 89 \\
\hline
\end{tabular}

at their open circuit potentials. The curves appear to be similar, consisting of a single semicircle in the high frequency region. However, it should be noted that although these curves appear to be similar with respect to their shape, they differ considerably in their size. This indicates that the same fundamental processes must be occurring on these coating but over a different effective area in each case.

To account for the corrosion of electroless Ni-Cu-P coating in 3\% sodium chloride solution, an equivalent electrical circuit model given in Figure 9 is used to simulate the metal/solution interface and to analyze the Nyquist plots. A similar analysis has been carried out by Lo et al. [43] to study the impedance behaviour of electroless $\mathrm{Ni}-\mathrm{P}$ coatings in $1 \mathrm{MNaOH}$ solution. It mainly consists of the following elements: solution resistance of the electrolyte $\left(R_{s}\right)$, constant phase element $(\mathrm{CPE})$, and charge transfer resistance of 


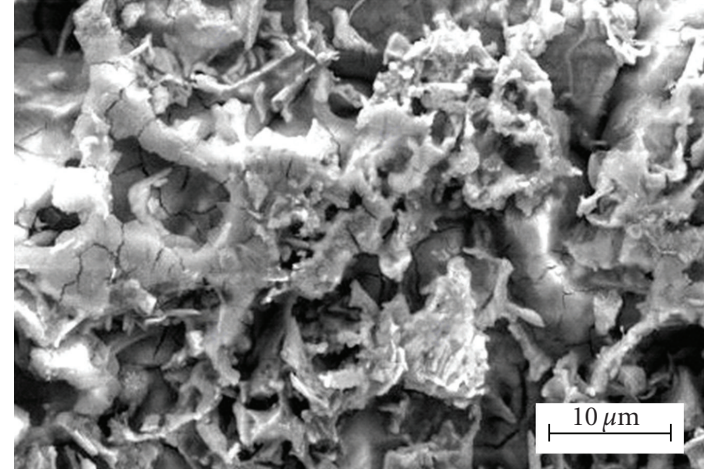

FIgURE 10: SEM of Ni-Cu-P alloy coatings immersed for 55 hours in $1 \mathrm{M} \mathrm{H}_{2} \mathrm{SO}_{4}$ media.

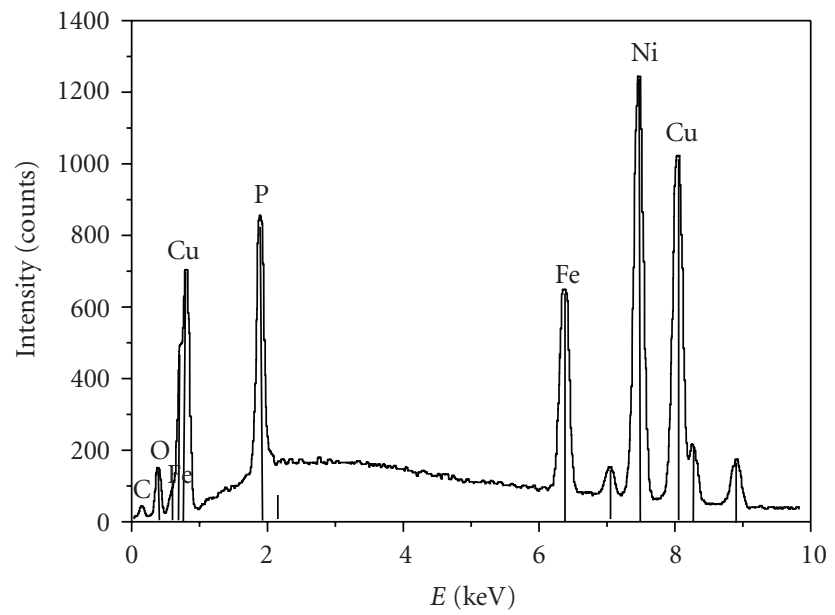

Figure 11: EDX spectra of Ni-Cu-P alloy coatings immersed in $1 \mathrm{M} \mathrm{H}_{2} \mathrm{SO}_{4}$ media for 55 hours.

the electrode/solution interface $\left(R_{\mathrm{ct}}\right)$. The constant phase element $(\mathrm{CPE})$ resembles a capacitor, but the phase angle is not $90^{\circ}$, which is usually used to explain the inhomogeneous system and some distribution of the value of physical property of the system.

The charge transfer resistance $R_{\mathrm{ct}}$ and double layer capacitance $C_{\mathrm{dl}}$ values obtained for electroless $\mathrm{Ni}-\mathrm{Cu}-\mathrm{P}$ and steel substrates are compiled in Table 3.

The occurrence of a single semicircle in the Nyquist plots indicates that the corrosion process of $\mathrm{Ni}-\mathrm{Cu}-\mathrm{P}$ coatings involves a single time constant. A similar conclusion of the existence of a single time constant was reported by Zeller [43], Van Der Kouwe [44], and Balaraju et al. [45] for the corrosion of electroless Ni-P coatings in sodium chloride and sodium hydroxide solutions at their open circuit potentials.

To further validate this view, the calculated $R_{\mathrm{ct}}$ and $C_{\mathrm{dl}}$ values are substituted for the proposed equivalent electrical circuit to obtain theoretical impedance values, which are also plotted along with the experimental impedance values Figure 8.
TABLe 3: Impedance data of uncovered ordinary steel and Ni-Cu-P alloy coatings after two hours in $3 \% \mathrm{NaCl}$.

\begin{tabular}{lccc}
\hline & $R_{\mathrm{ct}}\left(\Omega \cdot \mathrm{cm}^{2}\right)$ & $C_{\mathrm{ct}}\left(\mu \mathrm{F} \cdot \mathrm{cm}^{-2}\right)$ & $E_{Z}(\%)$ \\
\hline Uncovered ordinary steel & 440 & 1290 & - \\
Ni-Cu-P coating & 9210 & 17.3 & 96 \\
\hline
\end{tabular}

The degree of deviation resulting in the case of electroless $\mathrm{Ni}-\mathrm{Cu}-\mathrm{P}$ coatings might possibly be due to the decrease in the available metallic area for the charge transfer reaction, although the apparent area $\left(1 \mathrm{~cm}^{2}\right)$ remains equal to that of electroless Ni-Cu-P.

The high values of the charge transfer resistance $\left(R_{\mathrm{ct}}\right)$, obtained for the coating of the present study, imply a good corrosion protective ability of the Ni-Cu-P coating. The capacitance value obtained for electroless $\mathrm{Ni}-\mathrm{Cu}-\mathrm{P}$ coating is very low, of the order of $17 \mu \mathrm{F} / \mathrm{cm}^{2}$. This value is highly comparable to those obtained for similar coating elsewhere [43-46]. The $C_{\mathrm{dl}}$ value is linked to the porosity of the coating [47]. The low $C_{\mathrm{dl}}$ value confirms that the electroless $\mathrm{Ni}-\mathrm{Cu}-\mathrm{P}$ coating is relatively less porous in nature.

The protective efficiency is presented in Table 3. It is clear from that the $\mathrm{Ni}-\mathrm{Cu}-\mathrm{P}$ coating elaborated in our study resists better in neutral medium with a protective efficiency of about $96 \%$.

\subsubsection{Scanning Electron Microscopy}

(i) $\mathrm{H}_{2} \mathrm{SO}_{4}$ Media. SEM picture of electroless Ni-Cu-P alloy surface immersed in $1 \mathrm{M} \mathrm{H}_{2} \mathrm{SO}_{4}$ for 55 hours is presented in Figure 10. An examination of this micrograph shows a deterioration of the alloy surface. Indeed, we noticed the presence of cracking, the appearance of gaps, and separation of the deposit. However, an EDX spectrum (Figure 11) shows a prevalence of iron which is the substrate. This confirms the dissolution of a large proportion of the alloy deposited. An analysis of the coated part shows an increase of the copper peak. This is probably linked to a selective dissolution of nickel in this environment.

(ii) $\mathrm{HCl}$ Media. The micrographic (Figure 12), illustrating electroless Ni-Cu-P alloy surface immersed in $1 \mathrm{M} \mathrm{HCl}$ for 55 hours, shows the same phenomenon observed in the latter test, thus the appearance of cracks on the surface and the removal of the deposit.

The EDX spectrum shows, as in the case of the solution $1 \mathrm{M} \mathrm{H}_{2} \mathrm{SO}_{4}$, a predominance of iron. While the analysis (Figure 13) shows an increase of nickel peak, this is due to a selective dissolution of nickel in this medium.

Therefore, in both acidic media $\left(1 \mathrm{M} \mathrm{H}_{2} \mathrm{SO}_{4}\right.$ and $1 \mathrm{M} \mathrm{HCl}$ ) the dissolution of nickel is in agreement with other works done in $\mathrm{Ni}-\mathrm{P}$ and $\mathrm{Ni}-\mathrm{Cu}-\mathrm{P}[26,33]$.

(iii) 3\% $\mathrm{NaCl}$ Medium. SEM picture of electroless Ni-Cu-P coating surface, exposed to $3 \% \mathrm{NaCl}$ solution in Figure 14, 


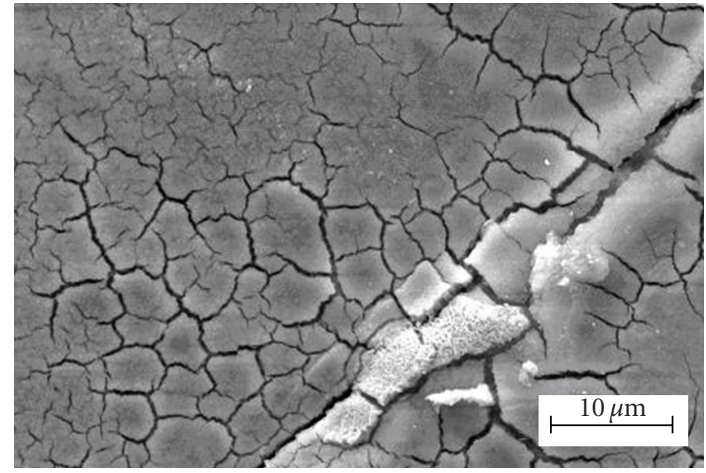

Figure 12: SEM image of Ni-Cu-P alloy coating immersed for 55 hours in $1 \mathrm{M} \mathrm{HCl}$.

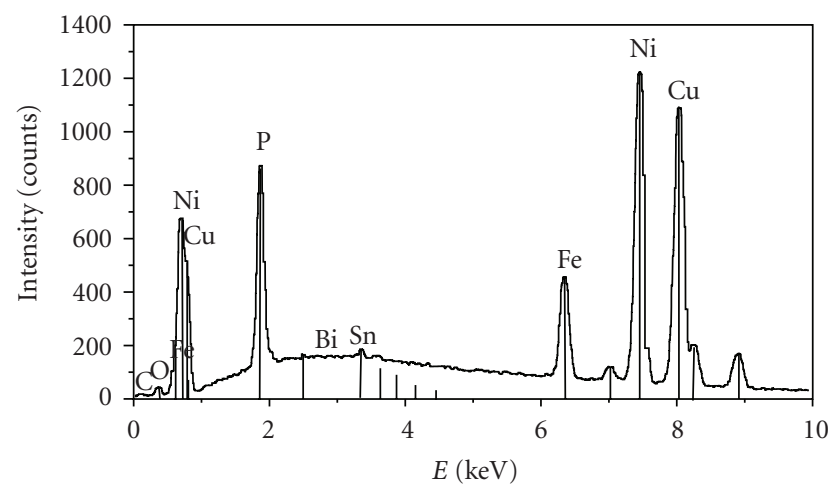

FIgURE 13: EDX spectra for removing range of $\mathrm{Ni}-\mathrm{Cu}-\mathrm{P}$ alloy coatings immersed in $1 \mathrm{M} \mathrm{HCl}$ for 55 hours.

shows heterogeneous layer of products and pitting corrosion caused by the action of $\mathrm{Cl}^{-}$ions.

EDX analysis of the part of the coating studied (Figure 15) shows a decrease in intensity peaks relating to copper; this may be linked to a selective dissolution of this element. However, the comparison between Figures 2 and 15 does not allow us to come to a decision on the mechanism of the dissolution. The dissolution process is not fast enough to make a resolve on its mechanism. A detailed study on this phenomenon will be carried out later.

\section{Conclusion}

Electroless $\mathrm{Ni}-\mathrm{Cu}-\mathrm{P}$ alloy coatings were deposited on the ordinary steel substrate using an autocatalytic plating technique from Ni-P bath containing $\mathrm{CuSO}_{4}, 5 \mathrm{H}_{2} \mathrm{O}$ in an acidic medium. The results showed that these coatings are amorphous, contain $11 \mathrm{wt} . \% \mathrm{Cu}$ and $12 \mathrm{wt} . \%$ $\mathrm{P}$, and present a nodular aspect. However, the electrochemical measurements and SEM/EDX analysis show that the mechanism of electroless $\mathrm{Ni}-\mathrm{Cu}-\mathrm{P}$ alloy dissolution depends on the nature of the medium. The protection

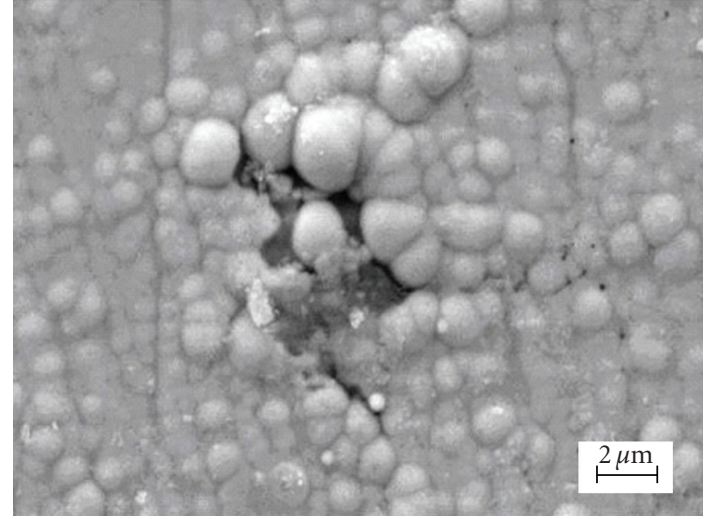

FIgURE 14: SEM image of Ni-Cu-P alloy coatings immersed for 55 hours in $3 \% \mathrm{NaCl}$ medium.

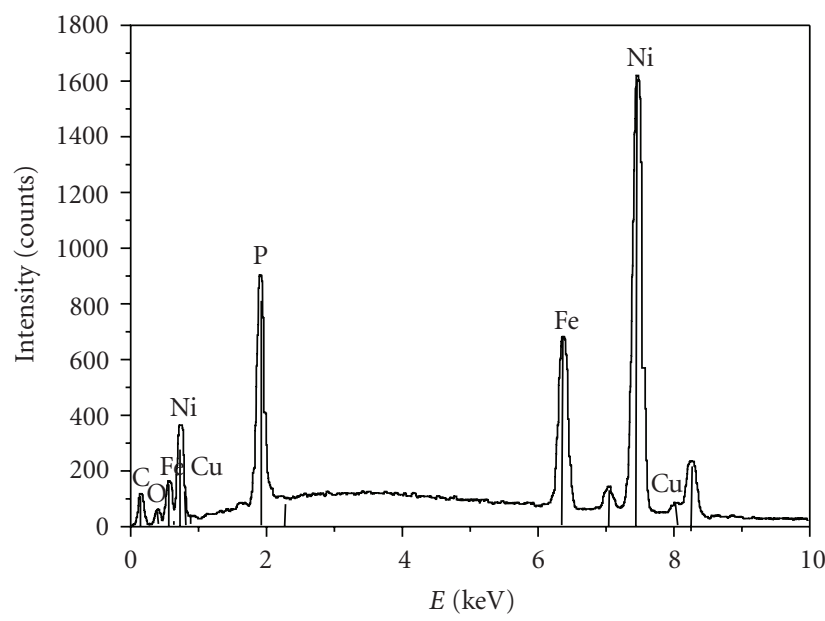

FIGURE 15: EDX spectra of Ni-Cu-P alloy coatings immersed in 3\% $\mathrm{NaCl}$ medium for 55 hours.

of the coating substrate is superior in neutral medium than in acidic medium.

\section{References}

[1] M. Cherkaoui, A. Srhiri, and E. Chassaing, "Electroless deposition of Ni-Cu-P alloys," Plating and Surface Finishing, vol. 11, pp. 68-71, 1992.

[2] M. Ebn Touhami et al., "Bain autocatalytique et procédé de dépôt d'alliages Ni-P,” Brevet français no. FR2754831, 1998.

[3] Q. Zhao, Y. Liu, H. Müller-Steinhagen, and G. Liu, "Graded Ni-P-PTFE coatings and their potential applications," Surface and Coatings Technology, vol. 155, no. 2-3, pp. 279-284, 2002.

[4] Y. Liu and Q. Zhao, "Effects of impurities on microstructure in Ni/YSZ-YSZ half-cells for SOFC," Transactions of the Institute of Metal Finishing, vol. 81, no. 5, p. 1, 2003.

[5] G. O. Mallory and J. B. Hajdu, Electroless Plating: Fundamentals and Applications, AESF, Orlando, Fla, USA, 1991.

[6] J. N. Balaraju and K. S. Rajam, "Electroless deposition of NiCu-P, Ni-W-P and Ni-W-Cu-P alloys," Surface and Coatings Technology, vol. 195, no. 2-3, pp. 154-161, 2005. 
[7] V. M. Dubin, S. D. Lopatin, and V. G. Sokolov, "Selective electroless $\mathrm{Ni}$ deposition on TiW underlayer for integrated circuit fabrication," Thin Solid Films, vol. 226, no. 1, pp. 8793, 1993.

[8] C.-J. Chen and K.-L. Lin, "Electroless Ni-Cu-P barrier between $\mathrm{Si} / \mathrm{Ti} / \mathrm{Al}$ pad and $\mathrm{Sn}-\mathrm{Pb}$ flip-chip solder bumps," IEEE Transactions on Components and Packaging Technologies, vol. 24, no. 4, pp. 691-697, 2001.

[9] L. L. Zhong, C. C. Lin, S. John, and D. Jeff, US Patent 6410, p. 104, 2002.

[10] J. Bielinski, A. Gildon, B. Socko, and A. Bielinska, "Studies regarding the optimization of solutions for electroless nickel plating. II. Additions of transition metal compounds," Metalloberflache Beschichten von Metall und Kunststoff, vol. 37, no. 7, pp. 300-305, 1983.

[11] W. Riedel, Electroless Plating, ASM International, Ohio, USA, 1991.

[12] N. Krasteva, V. Fotty, and S. Armyanov, "Thermal stability of Ni-P and Ni-Cu-P amorphous alloys," Journal of the Electrochemical Society, vol. 141, no. 10, pp. 2864-2867, 1994.

[13] N. Krasteva, S. Armyanov, J. Georgieva, N. Avramova, and V. Fotty, "Thermal stability of electroless NiMeP amorphous alloys," Journal of Electronic Materials, vol. 24, no. 8, pp. 941946, 1995.

[14] G. Lu and G. Zangari, "Corrosion resistance of ternary NiP based alloys in sulfuric acid solutions," Electrochimica Acta, vol. 47, no. 18, pp. 2969-2979, 2002.

[15] Y. Gao, L. Huang, Z. J. Zheng, H. Li, and M. Zhu, "The influence of cobalt on the corrosion resistance and electromagnetic shielding of electroless Ni-Co-P deposits on Al substrate," Applied Surface Science, vol. 253, no. 24, pp. 9470-9475, 2007.

[16] C. J. Chen and K. L. Lin, "The deposition and crystallization behaviors of electroless Ni-Cu-P deposits," Journal of The Electrochemical Society, vol. 146, p. 137, 1999.

[17] Y. Liu and Q. Zhao, "Study of electroless Ni-Cu-P coatings and their anti-corrosion properties," Applied Surface Science, vol. 228, no. 1-4, pp. 57-62, 2004.

[18] Y. W. Wang, C. G. Xiao, and Z. G. Deng, "Structure and corrosion resistance of electroless Ni-Cu-P," Plating and Surface Finishing, vol. 79, no. 3, p. 57, 1992.

[19] J. Georgieva and S. Armyanov, "Electroless deposition and some properties of Ni-Cu-P and Ni-Sn-P coatings," Journal of Solid State Electrochemistry, vol. 11, no. 7, pp. 869-876, 2007.

[20] H. Larhzil, M. Cissé, R. Touir, M. E. Touhami, and M. Cherkaoui, "Electrochemical and SEM investigations of the influence of gluconate on the electroless deposition of $\mathrm{Ni}-\mathrm{Cu}-$ P alloys," Electrochimica Acta, vol. 53, no. 2, pp. 622-628, 2007.

[21] A. Boukamp, "Users Manual Equivalent Circuit," ver. 4.51, 1993.

[22] Q. X. Mai, R. D. Daniels, and H. B. Harpalani, "Structural changes induced by heating in electroless nickel-phosphorus alloys," Thin Solid Films, vol. 166, pp. 235-247, 1988.

[23] J. N. Balaraju and S. K. Seshadri, "Preparation and characterization of electroless Ni-P and Ni-P-Si3N4 composite coatings," Transactions of the Institute of Metal Finishing, vol. 77, no. 2, pp. 84-86, 1999.

[24] J. N. Balaraju, C. Anandan, and K. S. Rajam, "Influence of codeposition of copper on the structure and morphology of electroless Ni-W-P alloys from sulphate- and chloride-based baths," Surface and Coatings Technology, vol. 200, no. 12-13, pp. 3675-3681, 2006.

[25] J. L. Carbajal and R. E. White, "Electrochemical production and corrosion testing of amorphous Ni-P," Journal of the Electrochemical Society, vol. 135, no. 12, pp. 2952-2957, 1988.
[26] R. B. Diegle, N. R. Sorensen, C. R. Clayton, M. A. Helfand, and Y. C. Yu, "XPS Investigation into the passivity of an amorphous Ni-20P alloy," Journal of the Electrochemical Society, vol. 135, no. 5, pp. 1085-1092, 1988.

[27] S. O. Niass, M. E. Touhami, N. Hajjaji, A. Srhiri, and H. Takenouti, "Inhibiting effect of quaternary phosphine on $\mathrm{Ni}$ P alloys in 1 M HSO," Journal of Applied Electrochemistry, vol. 31, no. 1, pp. 85-92, 2001.

[28] B. Elsener, M. Crobu, M. A. Scorciapino, and A. Rossi, "Electroless deposited Ni-P alloys: corrosion resistance mechanism," Journal of Applied Electrochemistry, vol. 38, no. 7, pp. 1053-1060, 2008.

[29] R. B. Diegle, N. R. Sorensen, and G. C. Nelson, "Dissolution of glassy Ni-P alloys in $\mathrm{H} / / 2 \mathrm{SO} / / 4$ and $\mathrm{HCl}$ electrolytes," Journal of the Electrochemical Society, vol. 133, no. 9, pp. 1769-1776, 1986.

[30] H. Habazaki, S. Q. Ding, A. Kawashima et al., "The anodic behavior of amorphous Ni-19P alloys in different amorphous states," Corrosion Science, vol. 29, no. 11-12, pp. 1319-1328, 1989.

[31] A. Krolikowski, "Passive characteristics of amorphous Ni-P alloys," in Modifications of Passive Films, P. Marcus, B. Baroux, and M. Keddam, Eds., pp. 119-122, The Institute of Materials, London, UK, 1994.

[32] A. Krolikowski, "Nature of anodic dissolution of amorphous Ni-P alloys," Materials Science Forum, vol. 185-188, pp. 799808, 1995.

[33] G. Liu, L. Yang, L. Wang, S. Wang, L. Chongyang, and J. Wang, "Corrosion behavior of electroless deposited Ni-Cu-P coating in flue gas condensate," Surface and Coatings Technology, vol. 204, no. 21-22, pp. 3382-3386, 2010.

[34] B. MacDougall, D. F. Mitchell, and M. J. Graham, "Use of electrochemical and suface-analytical techniques to characterize passive oxide films on nickel," Corrosion, vol. 38, no. 2, pp. 8591, 1982.

[35] E. Sikora and D. D. Macdonald, "Nature of the passive film on nickel," Electrochimica Acta, vol. 48, no. 1, pp. 69-77, 2002.

[36] M. G. Fontana and N. D. Greene, Corrosion Engineering, McGraw-Hill, New York, NY, USA, 1967.

[37] Q. Zhao and Y. Liu, "Comparisons of corrosion rates of Ni-P based composite coatings in $\mathrm{HCl}$ and $\mathrm{NaCl}$ solutions," Corrosion Science, vol. 47, no. 11, pp. 2807-2815, 2005.

[38] T. Mimani and S. M. Mayanna, "The effect of microstructure on the corrosion behaviour of electroless Ni-P alloys in acidic media," Surface and Coatings Technology, vol. 79, no. 1-3, pp. 246-251, 1996.

[39] H. Ashassi-Sorkhabi and S. H. Rafizadeh, "Effect of coating time and heat treatment on structures and corrosion characteristics of electroless Ni-P alloy deposits," Surface and Coatings Technology, vol. 176, no. 3, pp. 318-326, 2003.

[40] M. Crobu, A. Scorciapino, B. Elsener, and A. Rossi, "The corrosion resistance of electroless deposited nano-crystalline Ni-P alloys," Electrochimica Acta, vol. 53, no. 8, pp. 3364-3370, 2008.

[41] J. N. Balaraju, V. E. Selvi, V. K. W. Grips, and K. S. Rajam, "Electrochemical studies on electroless ternary and quaternary Ni-P based alloys," Electrochimica Acta, vol. 52, no. 3, pp. 1064-1074, 2006.

[42] Y. Gao, Z. J. Zheng, M. Zhu, and C. P. Luo, "Corrosion resistance of electrolessly deposited Ni-P and Ni-W-P alloys with various structures," Materials Science and Engineering A, vol. 381, no. 1-2, pp. 98-103, 2004.

[43] R. L. Zeller, "Electrochemical corrosion testing of high phosphorus electroless nickel in 5\% NaCl," Corrosion, vol. 47, no. 9, pp. 692-702, 1991. 
[44] E. T. van der Kouwe, "EIS as a means of evaluating electroless nickel deposits," Electrochimica Acta, vol. 38, no. 14, pp. 20932097, 1993.

[45] J. N. Balaraju, T. S. N. Sankara Narayanan, and S. K. Seshadri, "Evaluation of the corrosion resistance of electroless Ni-P and Ni-P composite coatings by electrochemical impedance spectroscopy," Journal of Solid State Electrochemistry, vol. 5, no. 5, pp. 334-338, 2001.

[46] P. H. Lo, W. T. Tsai, and J. Hung, "Electrochemical behavior of electroless plated Ni-P alloys in concentrated $\mathrm{NaOH}$ solution," Journal of the Electrochemical Society, vol. 142, no. 1, pp. 91-96, 1995.

[47] F. B. Growcock and R. J. Jasinski, "Time-resolved impedance spectroscopy of mild steel in concentrated hydrochloric acid," Journal of the Electrochemical Society, vol. 136, no. 8, pp. 2310 2314, 1989. 

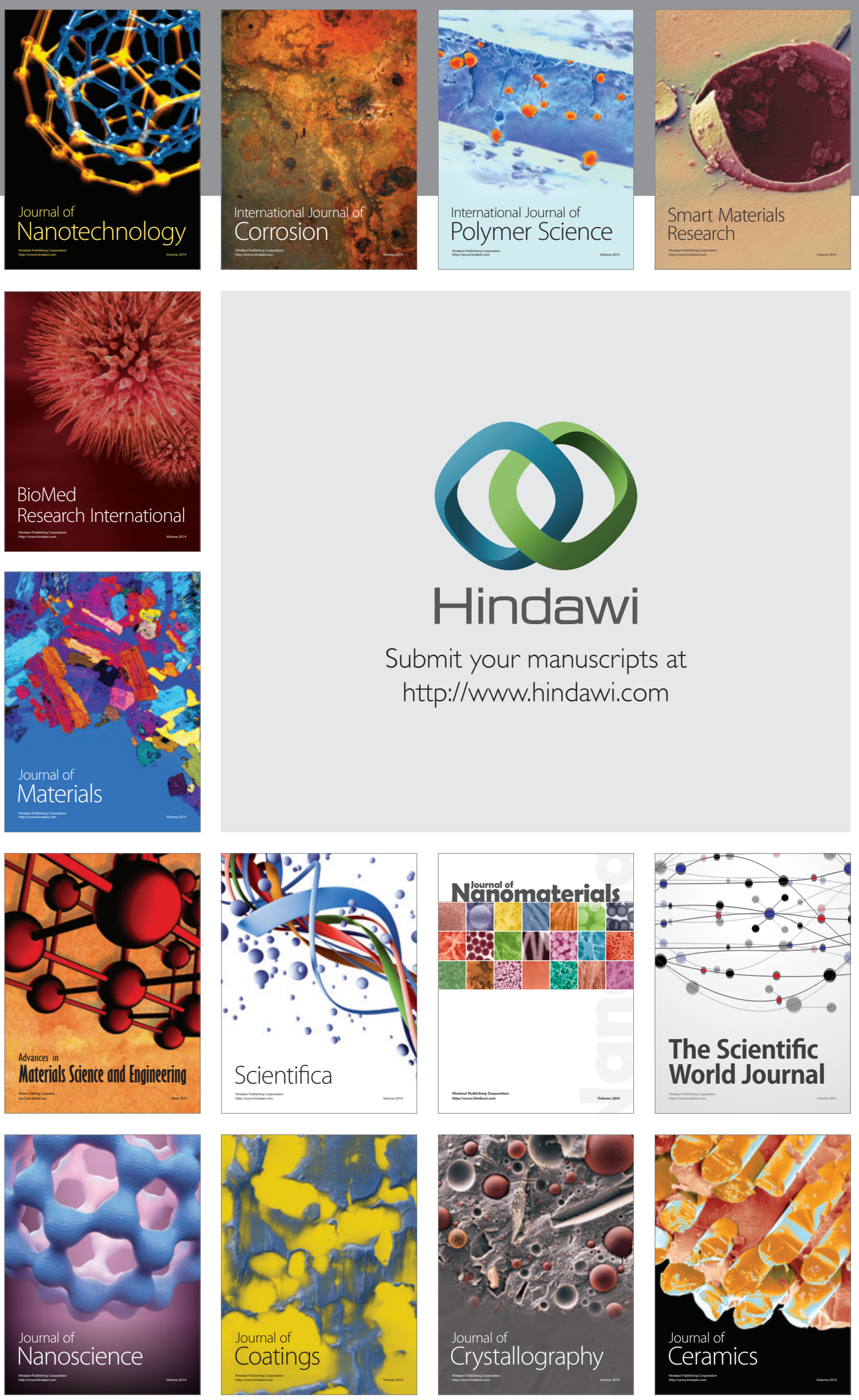

The Scientific World Journal

Submit your manuscripts at

http://www.hindawi.com

\section{World Journal}

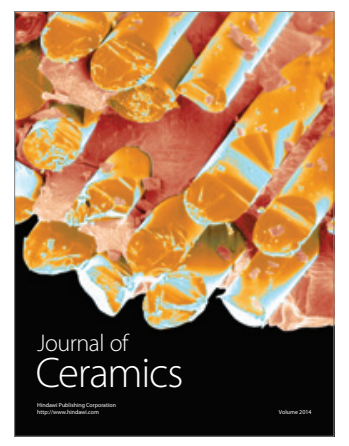

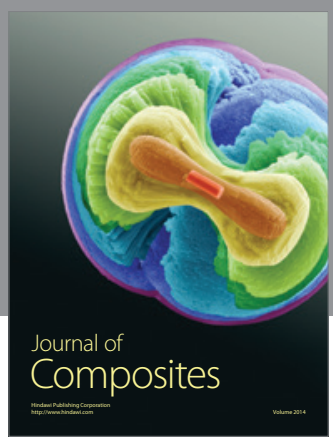
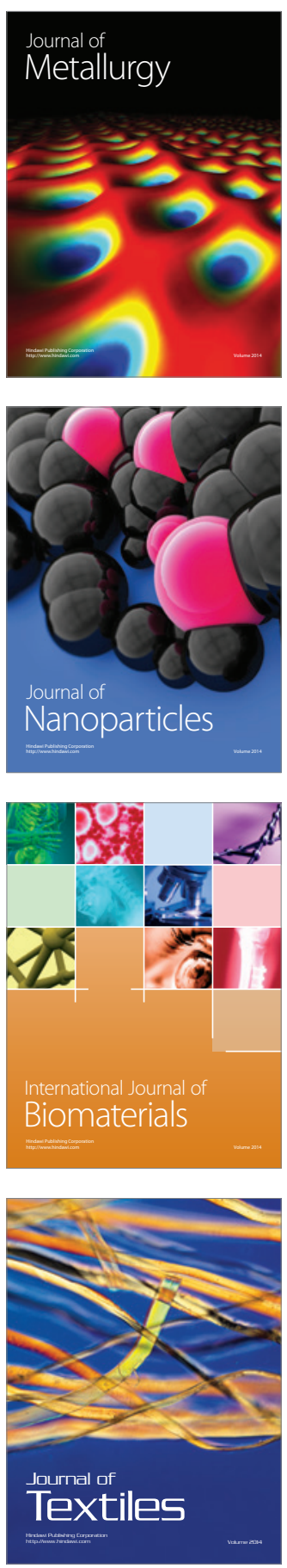